\section{THU0360 INCREASING IMPACT ON STRUCTURAL DAMAGE WITH INCREASING CUMULATIVE INFLAMMATION AT THE SI- JOINT QUADRANT LEVEL IN AXIAL SPONDYLOARTHRITIS - 5-YEAR DATA FROM THE DESIR COHORT}

Santiago Rodrigues-Manica ${ }^{1,2}$, Alexandre Sepriano $0^{2,3}$, Sofia Ramiro ${ }^{3,4}$, Robert B. M. Landewé ${ }^{5}$, Pascal Claudepierre ${ }^{6}$, Anna Moltón ${ }^{7}$, Maxime Dougados ${ }^{7}$, Miranda van Lunteren ${ }^{3}$, Désirée van der Heijde ${ }^{3} .{ }^{1}$ Hospital Egas Moniz, Rheumatology, Lisboa, Portugal; ${ }^{2}$ CEDOC, Lisboa, Portugal; ${ }^{3}$ Leiden University Medical Center (LUMC), Leiden, Netherlands; ${ }^{4}$ Zuyderland Medisch Centrum, Heerlen, Netherlands; ${ }^{5}$ Academic Medical Centre, Amsterdam, Netherlands; ${ }^{6}$ Hôpital HenriMondor Ap-Hp, Créteil, France; ${ }^{7}$ University Paris Descartes, Paris, France

Background: Axial inflammation is a key feature in axial $\mathrm{SpA}(\operatorname{axSpA})$. There is lack of data relative to the persistence of BME in the same anatomical quadrant (Q, 8 in total for both SIJ together), regardless of the overall presence of BME. Objectives: This study aims to investigate particular patterns of distribution of SIJ-BME across quadrants over time, their persistence over time, and their impact on clinical and structural outcomes.

Methods: Patients from the DESIR cohort (early axSpA according to the rheumatologist) with MRI-SIJ available at baseline, 2 and 5 years were included. Each image was scored by 3 trained central readers blinded to chronological order. BME was considered positive if detected in $\geq 1 / 6$ slices in each of the 8 quadrants, according to each individual reader. Four different patterns of BME over time were defined (no BME, sporadic pattern, fluctuating BME and persistent BME) considering all 8 quadrants (Figure). The effect of BME patterns on 5-year structural (mNY, mSASSS, $\geq 5$ erosions and/or fatty lesions in MRI-SIJ) and clinical outcomes (BASFI, BASMI and ASQoL) was evaluated using multilevel generalised estimating equations (GEE) models (taking the individual reader data into account) and linear regression (using the agreement of $\geq 2$ out of 3 ), as appropriate. All models were adjusted for relevant confounders including treatment (Table).

Results: In total, 136 patients were included (age 34 (SD 9) years, 50\% male, and 63\% HLA-B27 positive). 'No BME' was seen in 63 patients $(46 \%)$, the 'sporadic pattern' in 34 patients $(25 \%)$, the 'fluctuating pattern' was seen in 21 patients (15\%) and the 'persistent BME pattern' was seen in 18 patients (13\%). Compared to the 'no BME' pattern (reference), the 'sporadic' [OR $(95 \% \mathrm{Cl}): 2.1 \quad(1.0 ; 4.5)]$, 'fluctuating' [OR: 5.6 $(2.2 ; 14.4)]$ and 'persistent' [OR: $7.5(2.8 ; 19.6)]$ patterns were associated with higher likelihood to be mNY positive at 5-years, suggesting a gradient between cumulative inflammation and damage. Similar findings were observed for $\mathrm{mNY}$ as a continuous outcome variable and for $\geq 5$ erosions and/or fatty lesions on spinal MRI as outcomes, but not for mSASSS (Table). There was no association between the BME patterns and the clinical outcomes.

Conclusion: Only $13 \%$ of the patients showed persistent inflammation in the same Q over a 5 -year period and in $15 \%$ inflammation was fluctuating across different Qs. More structural damage was found in patients with increasing cumulative levels of local inflammation in the quadrant. Even when BME (temporarily) disappears there is an important effect on structural outcomes, and that effect $t$ is independent of treatment.

Disclosure of Interests: Santiago Rodrigues-Manica Grant/research support from: Novartis, MSD, Speakers bureau: Novartis, Alexandre Sepriano: None declared, Sofia Ramiro Grant/research support from: MSD, Consultant for: AbbVie, Lilly, MSD, Novartis, Pfizer, Sanofi, Speakers bureau: AbbVie, Lilly, MSD, Novartis, Pfizer, Sanofi, Robert B.M. Landewé: None declared, Pascal Claudepierre Consultant for: Honoraria from Novartis as steering committe of this survey, Anna Moltó: None declared, maxime dougados Grant/research support from: Eli Lilly and Company, Pfizer, AbbVie, and UCB Pharma, Consultant for: Eli Lilly and Company, Pfizer, AbbVie, and UCB Pharma, Miranda van Lunteren: None declared, Désirée van der Heijde Consultant for: AbbVie, Amgen, Astellas, AstraZeneca, Bristol-Myers Squibb, Boehringer Ingelheim, Celgene, Daiichi, EliLilly, Galapagos, Gilead, GlaxoSmithKline, Janssen, Merck, Novartis, Pfizer, Regeneron, Roche, Sanofi, Takeda, Union Chimique Belge

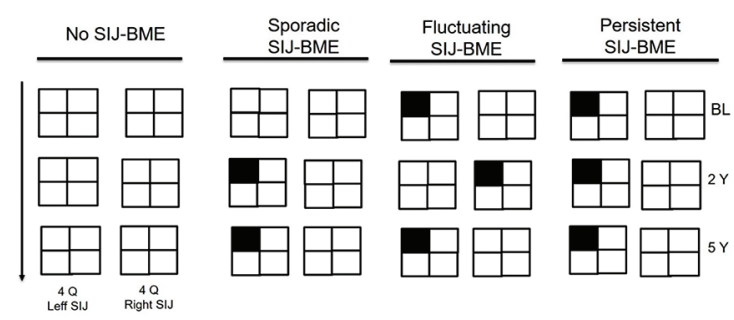

Figure. Graphical representation of examples of presentation of BME throughout time (baseline, 2 and 5 years) across 8 SIJ quadrants combined into four patterns. No BME: No BME in all observations; Sporadic BME: Other pattern of BME (not included in the previous; Fluctuating BME: Fluctuating BME at any of the 8 quadrants (e.g. 1-0-1 or 0-1-0) without simultaneous persistent BME in the remaining quadrants; Persistent BME: Constant BME, in at least on quadrant, regardless of the pattern of BME in the remaining quadrants).

Table - Association between SIJ-BME patterns and structural and clinical outcomes

\begin{tabular}{|c|c|c|c|c|c|}
\hline Outcome at 5 years & $\mathbf{N}$ & No BME & Sporadic BME & Fluctuating BME & Persistent BME \\
\hline $\mathrm{mNY}(0-8)^{\mathrm{a}}$ & 124 & (reference) & $0.4(0.1 ; 0.8)$ & $1.7(1.1 ; 2.3)$ & $2.3(1.6 ; 3.0)$ \\
\hline $\mathrm{mNY}\left(\right.$ yes/no) ${ }^{b}$ & 124 & (reference) & $2.1(1.0 ; 4.5)$ & $5.6(2.2 ; 14.4)$ & $7.5(2.8 ; 19.6)$ \\
\hline mSASSS $(0-72)^{\mathrm{a}}$ & 117 & (reference) & $-0.2(-0.9 ; 0.6)$ & $-0.3(-1.3 ; 0.3)$ & $-0.5(-1.3 ; 0.3)$ \\
\hline $\begin{array}{l}\geq 5 \text { erosions or/and fatty } \\
\text { lesions on MRI (yes/no) }\end{array}$ & 127 & (reference) & $2.9(1.4 ; 5.9)$ & $4.2(1.6 ; 10.8)$ & $8.1(4.1 ; 16.6)$ \\
\hline BASFI $(0-10)^{c}$ & 124 & (reference) & $-2.1(-8.8 ; 4.7)$ & $-5.9(-14.5 ; 2.7)$ & $0.2(-8.5 ; 8.9)$ \\
\hline $\operatorname{BASMI}(0-10)^{c}$ & 117 & (reference) & $-0.03(-0.44 ; 0.38)$ & $-0.43(-0.99 ; 0.13)$ & $0.03(-0.49 ; 0.56)$ \\
\hline ASQoL $(0-18)^{c}$ & 123 & (reference) & $-1.3(-2.9 ; 0.3)$ & $-2.2(-4.2 ;-0.2)$ & $-0.7(-2.7 ; 1.3)$ \\
\hline
\end{tabular}

(

All analyses are adjusted for symptom duration, sex, smoking status, HLA-B27, medication (NSAID, CSDMARD, bDMARD) and ASDAS.

Abstract THU0360 - Figure 1

DOI: 10.1136/annrheumdis-2019-eular.4994

\begin{tabular}{|l|l|}
\hline THU0361 & DIAGNOSTIC PERFORMANCE OF MRI LESIONS IN THE \\
SACROILIAC JOINTS ACCORDING TO UPDATED ASAS \\
LESION DEFINITIONS: A CENTRAL READER \\
ASSESSMENT OF MRI SCANS FROM THE \\
ASSESSMENTS IN SPONDYLOARTHRITIS \\
CLASSIFICATION COHORT
\end{tabular}

Walter P Maksymowych ${ }^{1,2}$, Robert G Lambert ${ }^{1}$, Xenofon Baraliakos ${ }^{3}$, Susanne Juhl Pedersen ${ }^{4}$, Pedro Machado ${ }^{5}$, Joachim Sieper ${ }^{6}$, Stephanie Wichuk ${ }^{1}$, Denis Poddubnyy ${ }^{6}$, Joel Paschke ${ }^{2}$, Mikkel Ǿstergaard ${ }^{4}$, Ulrich Weber ${ }^{7}{ }^{1}$ University of Alberta, Edmonton, Canada; ${ }^{2}$ CaRE Arthritis, Edmonton, Canada;

${ }^{3}$ Rheumazentrum Ruhrgebiet, Herne, Germany; ${ }^{4}$ Rigshospitalet University of Copenhagen, Copenhagen, Denmark; ${ }^{5}$ University College London, London, United Kingdom; ${ }^{6}$ Charité Universitätsmedizin, Berlin, Germany, ${ }^{7}$ University of South Denmark, Odense, Denmark

Background: The ASAS MRI group has generated updated lesion definitions for MRI lesions in the SIJ. While the ASAS definition of a positive MRI for classification purposes remains unchanged, these additional ASAS definitions for active and structural lesions may also be of diagnostic value. It is important to understand their relative contribution and complementarity as diagnostic indicators.

Objectives: To determine optimal cut-offs for the number of SIJ quadrants with MRI lesions reflecting diagnosis of axSpA in patients with undiagnosed back pain.

Methods: MRI lesions on baseline scans from the ASAS Classification Cohort were recorded by 7 experienced readers from the ASAS-MRI group. Detailed scoring of lesions per SIJ quadrant (SPARCC SIJ quadrantic method) was available for assessment of bone marrow edema (BME) and structural lesions in 158 and 146 cases, respectively, who were diagnosed by the local rheumatologist at baseline. Of these, 86 and 79 cases with BME and structural lesion data, respectively, were also diagnosed by the local rheumatologist at follow up (mean 4.4 years). We calculated sensitivity and specificity for varying numbers of SIJ quadrants with MRI lesions with rheumatologist diagnosis of axSpA at baseline and follow up as gold standard.

Results: Lesion cut-offs based on BME were most sensitive for diagnosis at baseline and follow up but erosion- and fatty-lesion cut-offs were more specific (Table). At least 2 SIJ quadrants with erosion or fat metaplasia were associated with $>90 \%$ specificity for the diagnosis of axSpA. There was also a consistent improvement in the sensitivity and specificity performance of cut-offs based on erosions and fatty lesions according to diagnosis at baseline and at follow up after 4.4 years but not for cut-offs based on BME. Lesion cut-offs that combined BME and/or erosion enhanced sensitivity without compromising specificity. 
Abstract THU0361 -Table 1

\begin{tabular}{|c|c|c|c|c|}
\hline \multirow{2}{*}{$\begin{array}{l}\text { MRI lesion SIJ quadrant } \\
\text { cut-offs, } \\
\text { Agreement by } \geq 2 \text { central } \\
\text { reader data }\end{array}$} & \multicolumn{2}{|c|}{$\begin{array}{l}\text { axSpA Diagnosed at } \\
\text { Baseline }\end{array}$} & \multicolumn{2}{|c|}{$\begin{array}{l}\text { axSpA Diagnosed at } \\
\text { Follow up }\end{array}$} \\
\hline & $\begin{array}{l}\text { Sensitivity } \\
(95 \% \mathrm{Cl})\end{array}$ & $\begin{array}{c}\text { Specificity } \\
(95 \% \mathrm{Cl})\end{array}$ & $\begin{array}{c}\text { Sensitivity } \\
(95 \% \mathrm{Cl})\end{array}$ & $\begin{array}{l}\text { Specificity } \\
(95 \% \mathrm{Cl})\end{array}$ \\
\hline BME Score $\geq 2$ & $\begin{array}{l}50.0(40.6- \\
59.4)\end{array}$ & $\begin{array}{c}82.5(70.1- \\
91.3)\end{array}$ & $\begin{array}{c}46.5(34.5- \\
58.7)\end{array}$ & $\begin{array}{c}86.4(65.1 \\
97.1)\end{array}$ \\
\hline BME Score $\geq 3$ & $\begin{array}{c}40.5(31.5- \\
50.0)\end{array}$ & $\begin{array}{c}94.7(85.4- \\
98.9)\end{array}$ & $\begin{array}{c}33.8(23.0- \\
46.0)\end{array}$ & $\begin{array}{c}90.9(70.8 \\
98.9)\end{array}$ \\
\hline Erosion Score $\geq 2$ & $\begin{array}{c}35.3(26.7- \\
44.8)\end{array}$ & $\begin{array}{c}93.0(83.0- \\
98.1)\end{array}$ & $\begin{array}{c}33.8(23.0- \\
46.0)\end{array}$ & $\begin{array}{c}95.5(77.2 \\
99.9)\end{array}$ \\
\hline Erosion Score $\geq 3$ & $\begin{array}{c}31.0(22.8- \\
40.3)\end{array}$ & $\begin{array}{c}93.0(83.0- \\
98.1)\end{array}$ & $\begin{array}{c}33.8(23.0- \\
46.0)\end{array}$ & $\begin{array}{c}95.5(77.2 \\
99.9)\end{array}$ \\
\hline Fatty lesion $\geq 2$ & $\begin{array}{c}34.5(25.9- \\
43.9)\end{array}$ & $\begin{array}{c}93.0(83.0- \\
98.1)\end{array}$ & $\begin{array}{c}38.0(26.8- \\
50.3)\end{array}$ & $\begin{array}{c}95.5(77.2 \\
99.9)\end{array}$ \\
\hline Fatty lesion $\geq 3$ & $\begin{array}{c}31.9(23.6- \\
41.2)\end{array}$ & $\begin{array}{c}94.7(85.4- \\
98.9)\end{array}$ & $\begin{array}{c}35.2(24.2- \\
47.5)\end{array}$ & $\begin{array}{c}95.5(77.2 \\
99.9)\end{array}$ \\
\hline Sclerosis $\geq 2$ & $\begin{array}{c}32.8(24.3- \\
42.1)\end{array}$ & $\begin{array}{c}82.5(70.1- \\
91.3)\end{array}$ & $\begin{array}{c}29.6(19.3- \\
41.6)\end{array}$ & $\begin{array}{c}90.9(70.8 \\
98.9)\end{array}$ \\
\hline Sclerosis $\geq 3$ & $\begin{array}{c}28.5(20.5- \\
37.6)\end{array}$ & $\begin{array}{c}82.5(70.1- \\
91.3)\end{array}$ & $\begin{array}{c}26.8(16.9- \\
38.6)\end{array}$ & $\begin{array}{c}90.9(70.8 \\
98.9)\end{array}$ \\
\hline $\begin{array}{l}\text { BME score } \geq 1 \text { and } \\
\text { Erosion score } \geq 1\end{array}$ & $\begin{array}{c}36.1(26.6- \\
46.5)\end{array}$ & $\begin{array}{l}92.1(78.6- \\
98.3)\end{array}$ & $\begin{array}{c}32.8(21.3- \\
46.0)\end{array}$ & $\begin{array}{c}84.6(54.6 \\
98.1)\end{array}$ \\
\hline $\begin{array}{l}\text { BME score } \geq 2 \text { and/or } \\
\text { Erosion score } \geq 1\end{array}$ & $\begin{array}{l}58.8(48.3- \\
68.7)\end{array}$ & $\begin{array}{c}81.6(65.7- \\
92.3)\end{array}$ & $\begin{array}{c}49.2(36.1- \\
62.3)\end{array}$ & $\begin{array}{c}84.6(54.6 \\
98.1)\end{array}$ \\
\hline $\begin{array}{l}\text { BME score } \geq 2 \text { and/or } \\
\text { Erosion score } \geq 2\end{array}$ & $\begin{array}{l}58.8(48.3- \\
68.7)\end{array}$ & $\begin{array}{c}81.6(65.7- \\
92.3)\end{array}$ & $\begin{array}{c}49.2(36.1- \\
62.3)\end{array}$ & $\begin{array}{c}84.6(54.6 \\
98.1)\end{array}$ \\
\hline $\begin{array}{l}\text { BME score } \geq 3 \text { and/or } \\
\text { Erosion score } \geq 1\end{array}$ & $\begin{array}{c}51.6(41.2- \\
61.8)\end{array}$ & $\begin{array}{c}86.8(69.9- \\
93.4)\end{array}$ & $\begin{array}{c}39.3(27.1- \\
52.7)\end{array}$ & $\begin{array}{c}84.6(54.6 \\
98.1)\end{array}$ \\
\hline
\end{tabular}

Conclusion: The updated ASAS definitions based on the presence of MRI lesions in 2-3 SIJ quadrants have comparable diagnostic performance. This performance improves for erosion and fatty lesion cut-offs after follow up.

Disclosure of Interests: Walter P Maksymowych Grant/research support from: AbbVie, Pfizer, Janssen, Novartis, Consultant for: AbbVie, Eli Lilly, Boehringer, Galapagos, Janssen, Novartis, Pfizer and UCB Pharma; Chief Medical Officer for Canadian Research and Education Arthritis, Robert G Lambert Consultant for: Bioclinica, Parexel, Abbvie, Xenofon Baraliakos Grant/research support from: AbbVie, Boehringer Ingelheim, Bristol-Myers Squibb, Celgene, Centocor, Chugai, Janssen, MSD, Novartis, Pfizer Inc, Roche and UCB, Grant/research support from: AbbVie, Pfizer, Merck Sharp \& Dohme, UCB Pharma, Novartis, Consultant for: AbbVie, BristolMyers Squibb, Boehringer Ingelheim, Celgene, Chugai, Janssen Biologics, Novartis, Pfizer, UCB Pharma, Galapagos, Speakers bureau: AbbVie, Chugai, Janssen, Novartis, Pfizer, UCB Pharma, Susanne Juhl Pedersen: None declared, Pedro Machado Consultant for: Abbvie, BMS, Celgene, Janssen, MSD, Novartis, Pfizer, Roche and UCB, Speakers bureau: Abbvie, BMS, Celgene, Janssen, MSD, Novartis, Pfizer, Roche and UCB, Joachim Sieper Consultant for: Abbvie, Böhringer Ingelheim, Janssen, Lilly, Merck, Mylan, Novartis, Pfizer, UCB., Speakers bureau: Abbvie, Böhringer Ingelheim, Janssen, Lilly, Merck, Mylan, Novartis, Pfizer, UCB., Stephanie Wichuk: None declared, Denis Poddubnyy Grant/research support from: AbbVie, Merck Sharp \& Dohme, Novartis, Consultant for: AbbVie, Bristol-Myers Squibb, Janssen, Merck Sharp \& Dohme, Novartis, Pfizer, UCB Pharma, Speakers bureau: AbbVie, Bristol-Myers Squibb, Janssen, Merck Sharp \& Dohme, Novartis, Pfizer, Roche, UCB Pharma, Joel Paschke: None declared, Mikkel Ǿstergaard Grant/research support from: Abbvie, Celgene, Centocor, Merck, Novartis, Consultant for: Abbvie, BMS, Boehringer-Ingelheim, Celgene, Eli Lilly, Hospira, Janssen, Merck, Novartis, Novo, Orion, Pfizer, Regeneron, Roche, and UCB, Speakers bureau: Abbvie, BMS, Boehringer-Ingelheim, Celgene, Eli Lilly, Hospira, Janssen, Merck, Novartis, Novo, Orion, Pfizer, Regeneron, Roche, and UCB, Ulrich Weber Consultant for: Abbvie

DOI: 10.1136/annrheumdis-2019-eular.6455
THU0362

THE IMPACT OF A REFERRAL ALGORITHM FOR AXIAL SPONDYLOARTHRITIS: A FOUR MONTH FOLLOW-UP OF PATIENT REPORTED OUTCOMES

Maha Jamal Abdelkadir ${ }^{1}$, Amber Korver ${ }^{2}$, Martijn Kuijper ${ }^{3}$, Deirisa Lopes Barreto ${ }^{3}$, Cathelijne Appels ${ }^{4}$, Anneke Spoorenberg ${ }^{5}$, Bart Koes ${ }^{6}$, Johanna Hazes ${ }^{2}$, Lonneke van Hoeven ${ }^{2}$, Angelique Weel ${ }^{3} .{ }^{1}$ Maasstad hospital, Rheumatology, Rotterdam, Netherlands, ${ }^{2}$ Erasmus MC University Medical Centre, Rheumatology, Rotterdam, Netherlands; ${ }^{3}$ Maasstad hospital, Rheumatology and clincal immunology, Rotterdam, Netherlands; ${ }^{4}$ Amphia hospital, Rheumatology, Breda, Netherlands; ${ }^{5}$ University Medical Centre Groningen, Rheumatology and clincal immunology, Groningen, Netherlands; ${ }^{6}$ Erasmus MC University Medical Centre, General practice, Rotterdam, Netherlands

Background: A substantial amount of patients with chronic low back pain (CLBP) have axial spondyloarthritis (axSpA), but early recognition of these patients is difficult for general practitioners (GPs). ${ }^{1}$ As a result, several referral strategies have been developed to help physicians identify patients at risk for axSpA within the large group of CLBP patients. ${ }^{2}$ Most referral strategies were developed in secondary care patients. The only referral strategy that was developed and validated in primary low back patients is the CaFaSpA strategy. ${ }^{3}$ An essential step before implementing referral strategies in daily clinical practice is the execution of an impact analysis. ${ }^{4}$

Objectives: The purpose of this study is to assess the impact of using a referral strategy on patient outcomes in young primary care patients with CLBP at risk for axSPA.

Methods: A clustered randomized controlled trial was performed in a primary care setting (ClinicalTrials.gov Identifier: NCT01944163). Each cluster contained the general practices from a single primary care practice and their included patients. Clusters were randomized to either the intervention (use of CaFaSpA referral strategy) or the control group (usual care). Primary outcome was disability caused by CLBP, measured with the Roland Morris Disability Questionnaire (RMDQ) at baseline and 4 months. Secondary outcome was axSpA diagnosis made by a rheumatologist. A linear mixed-effects model was used to analyze mean change in RMDQ score. Results: In total 679 patients were included within 93 GP clusters. Sixtyfour percent of our study population were female and mean age was 36 years. Median RMDQ score at baseline was 8 (IQR 4-12) in both groups. Compared to baseline, mean RMDQ score decreased by 0.74 points at 4 months (intervention) and by 0.46 points (control) (Fig. 1). This decrease did not significantly differ between groups $(p=0.50)$. Eight percent of the finally referred patients in the intervention group, received an axSPA diagnosis (8\%) from the rheumatologist. The median RMDQ among patients who visited the rheumatologist decreased from 8 to 5 after 4 month. This was not statistically significant ( $p$-value $=0.17$ ).

Conclusion: Although the CaFaSpA referral strategy did not have an early impact on disability caused by CLBP, it can be used as a screening strategy for GPs to identify axSpA patients.

\section{REFERENCES:}

[1] Jois RN, Macgregor AJ, Gaffney K. Recognition of inflammatory back pain and ankylosing spondylitis in PC. Rheumatology (Oxford) 2008;47:13641366.

[2] Abawi O, van den Berg R, van der Heijde D, van Gaalen FA. Evaluation of multiple referral strategies for axial spondyloarthritis in the SPondyloArthritis Caught Early (SPACE) cohort. RMD Open 2017 Apr 7;3(1):e0003892016-000389. eCollection 2017.

[3] van Hoeven L, Vergouwe Y, de Buck PD, Luime JJ, Hazes JM, Weel AE. External Validation of a Referral Rule for Axial Spondyloarthritis in Primary Care Patients with Chronic Low Back Pain. PLoS One 2015 Jul 22;10(7): e0131963.

[4] Moons KG. Kengne AP, Grobbee DE, Risk prediction models: II. External validation, model updating, and impact assessment. Heart. 2012;98 (9):691-8.

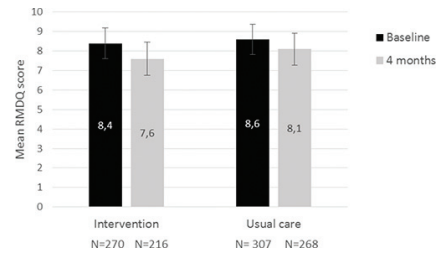

Abstract THU0362 - Figure 1. Estimated mean RMDQ scores over time for the overall intervention and usual care group.

Bars indicate $95 \%$ confidence intervals for the mean estimates. 